University of Wollongong

Research Online

Faculty of Business - Papers (Archive)

Faculty of Business and Law

2013

Modelling the impact of mHealth service quality on satisfaction, continuance and quality of life

\author{
Shahriar Akter \\ University of Wollongong, sakter@uow.edu.au \\ John D'Ambra \\ University of New South Wales \\ Pradeep Ray \\ University Of New South Wales, p.ray@unsw.edu.au \\ Umme Hani \\ University of Western Sydney
}

Follow this and additional works at: https://ro.uow.edu.au/buspapers

Part of the Business Commons

Research Online is the open access institutional repository for the University of Wollongong. For further information contact the UOW Library: research-pubs@uow.edu.au 


\title{
Modelling the impact of mHealth service quality on satisfaction, continuance and quality of life
}

\begin{abstract}
Understanding the impact of service quality on economic and social outcomes is critical to extend the focus of IT service research. This study evaluates the impact of quality on both these dimensions in mHealth using a cross disciplinary approach. The conceptual model is rooted in the traditional cognitionaffective-conation chain but explicitly incorporates convenience, confidence, cooperation, care and concern as the primary dimensions of mHealth quality. The model is validated in the context of a business-to-consumer mHealth services using partial least squares path modelling. The results confirm that service quality has both direct and indirect impact on continuance intentions (i.e. economic outcome) and quality of life (i.e. social outcome). In this relationship, satisfaction plays the key mediating role, whereas service quality does not have any moderating effect. Research implications point to scale and sustain this new healthcare paradigm by linking service quality to satisfaction, continuance intentions and quality of life.
\end{abstract}

\section{Keywords}

era2015

Disciplines

Business

\section{Publication Details}

Akter, S., D'Ambra, J., Ray, P. \& Hani, U. (2013). Modelling the impact of mHealth service quality on satisfaction, continuance and quality of life. Behaviour and Information Technology, OnlineFirst 1-17. 


\title{
Modelling the Impact of mHealth Service Quality on Satisfaction, Continuance and Quality of Life
}

\author{
Shahriar Akter* \\ School of Management \& Marketing, University of Wollongong, Australia, email: \\ sakter@uow.edu.au \\ * Corresponding author
}

John D'Ambra

Australian School of Business, University of New South Wales, Australia, email: j.dambra@unsw.edu.au

Pradeep Ray

Australian School of Business, University of New South Wales, Australia, email: p.ray@unsw.edu.au

Umme Hani

Sydney Graduate School of Management, University of Western Sydney, Australia, email: snigdha_hani@live.com 


\section{Modelling the Impact of mHealth Service Quality on Satisfaction, Continuance and Quality of Life}

Understanding the impact of service quality on economic and social outcomes is critical to extend the focus of IT service research. This study evaluates the impact of quality on both these dimensions in mHealth using a cross disciplinary approach. The conceptual model is rooted in the traditional cognition - affectiveconation chain but explicitly incorporates convenience, confidence, cooperation, care and concern as the primary dimensions of mHealth quality. The model is validated in the context of a business-to-consumer (B2C) mHealth services using partial least squares (PLS) path modelling. The results confirm that service quality has both direct and indirect impact on continuance intentions (i.e., economic outcome) and quality of life (i.e., social outcome). In this relationship, satisfaction plays the key mediating role, whereas service quality does not have any moderating effect. Research implications point to scale and sustain this new healthcare paradigm by linking service quality to satisfaction, continuance intentions and quality of life.

Keywords: mHealth, service quality, satisfaction, continuance, quality of life 


\section{Introduction}

The global economy is becoming characterized by services with more than $70 \%$ contribution in GDP from the services sector (Ostrom et al. 2010). Health care is one of the fastest growing sectors in the services economy. The growth of this sector is expected to be sustained through a critical evaluation of its impact on the success of firms, the well being of societies and the quality of consumers' lives worldwide (Bitner and Brown 2008). Though health care is arguably the most important service with a pervasive impact on daily life, it is a deeply troubled sector (Berry and Bendapudi 2008). The health care system in the world is on a depressing path, with a deadly combination of limited access to care, uneven quality and high costs (Porter and Teisberg, 2006). In this context, the introduction of information and communication technologies (ICT), especially the application of mHealth, has created the potential to transform healthcare delivery by making it more accessible, affordable and available. According to the World Health Organization Report (2008), "The world has better technology and better information to allow it to maximize the return on transforming the functioning of health systems."

"mHealth", a new paradigm of the emerging IT artefact, is the application of mobile communications - such as mobile phones and PDAs-to deliver right time health services to customers (or, patients). In the health care sector, mHealth is a transformative IT service for shifting the care paradigm from crisis intervention to promoting wellness, prevention, and self-management (Kaplan and Litewka 2008). As a transformative service, mHealth centers on "creating uplifting changes and improvements in the well-being of both individuals and communities" (Ostrom et al. 2010). Although this service creates positive changes, growing concerns revolve around perceived quality of such services due to lack of reliability of the service 
platform, knowledge and competence of the provider, privacy and security of information services, and above all, their overall effects on patient satisfaction, continuance intentions and quality of life (Akter and Ray 2010; Dagger and Sweeney 2006, Dagger et al. 2007, Ivatury et al. 2009, Mechael 2009, Varshney 2005). As such, the impact of perceived quality on critical service outcomes becomes a critical dimension to determine the success or failure of mHealth platform.

However, research is scant in IT services that have models to analyze these relationships (Ostrom et al. 2010). A review of the literature reveals that most of the research in this domain (i.e., mHealth) remains largely anecdotal, fragmented and atheoretical (Akter et al. 2011, Chatterjee et al. 2009). Thus, this study aims to model the impact of perceived service quality (SQ) on satisfaction (SA), continuance intentions (CI) and quality of life (QOL) in the context of a B2C mHealth services. This modelling extends the scope of technology-business alignment in transformative IT services research by developing an mHealth quality model and framing its overall impact on individual, economic and social outcomes.

The paper is organized as follows: section 2 provides an overview of the model, definitions of the key constructs, and a detailed development of the hypotheses. Section 3 describes the methodology, including sampling and the instrument to measure the conceptual model. Section 4 presents the results of the hypothesis testing and finally, section 5 discusses research implications, limitations and future research directions. 


\section{Conceptual Framework and Research Hypotheses}

The proposed research model explains the dynamics of mHealth service quality by encapsulating its components and consequences (see Figure 1). The model extends knowledge by conceptualizing mHealth service quality (SQ) and modelling its overall impact on satisfaction (SA), intention to continue using (CI) and quality of life (QOL). Although service quality is a critical parameter in any health service, there is a paucity of research which has adequately focused on mHealth service quality dynamics (Akter and Ray 2010, Earth Institute 2010, Ivatury et al. 2009, Kahn et al. 2010, WHO 2011). Thus this study fills this void by developing a multi-dimensional mHealth service quality model and framing its effects on critical service outcomes. The proposed model substantially differs from the extant theoretical frameworks (e.g., Andaleeb 2001, Brady and Cronin 2001, Dagger et al. 2007, Fassnacht and Koese 2006, Jia et al. 2008, Parasuraman et al. 1988, 2005) by articulating service quality (SQ) in mHealth and evaluating its overall effects on individual benefit (i.e., SA), economic return (i.e., CI) and societal welfare (i.e., QOL).

The conceptual model (Figure 1) is based on the literature in marketing, information systems and health care as the study focuses on a technology mediated health service platform. In service research, such an interdisciplinary approach is important and necessary to adequately address the challenges and opportunities (Ostrom et al. 2010). The conceptual model elucidates an overview of associations in terms of cognitiveaffective-conative framework (Bhattacherjee 2001, Cronin and Taylor 1992, Chiou et al. 2006; Dagger et al. 2007; Oliver 1997, Taylor and Baker 1994, Woodside et al. 1989). 


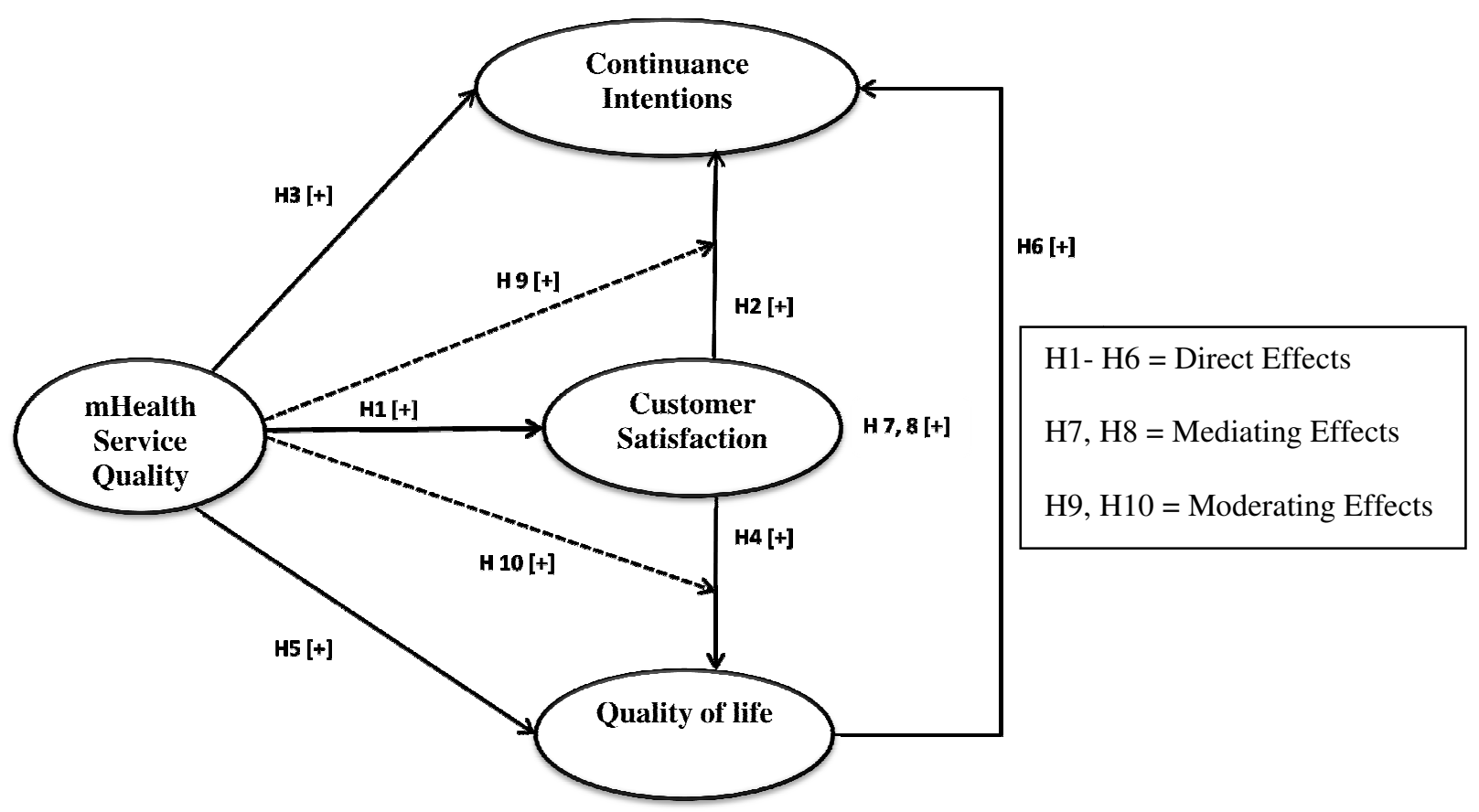

Figure1: Research Model

The model links consumer beliefs, affect, and intention within the traditional consumer attitude structure. This relationship simplifies quality dominant decision making process for a transformative IT service platform (e.g., B2C mHealth care) with an effect on economic (i.e., continuance intentions) and social (i.e., quality of life) outcomes. The model conceptualizes service quality as a higher order construct, which has an influence on satisfaction, continuance intentions and quality of life. In this relationship, satisfaction plays the key mediating role between SQ - CI and SQ - QOL. This study also explores the moderating effects of SQ in the satisfaction-CI link as well as satisfaction-QOL link. In the following sections, the study defines each construct and presents justification for all the hypotheses with further elaboration regarding the proposed relationships. 


\subsection{Service Quality}

Service quality is an important and particularly relevant construct in virtually all service business (Voss et al. 2004). It is a powerful concept because of its strong relationship with customer satisfaction (Andaleeb 2008; Cronin and Taylor 1992, Dabholkar et al. 2000; Oliver 1993, Taylor and Baker 1994), purchase intention (Dagger et al. 2007; Dagger and Sweeney 2006) and firm's performance (Fassnacht and Koese 2006, Sousa \& Voss 2006). Research in this arena still remains 'unresolved' (Caruana et al. 2000, Jia et al. 2008) due to its 'elusive' nature (Ma et al. 2005, Parasuraman et al. 1985, 2005). Indeed, this concept remains difficult to conceptualize (Brady and Cronin 2001, Chiou et al. 2006, Dagger et al. 2007) and "far from conclusive" (Atbanassopoulos 2000, p. 191). This study defines service quality as a consumer's judgment of, or impression about, an entity's overall excellence or superiority (Dagger et al. 2007). In health care, customers or patients play a critical role in defining quality and designing the service delivery systems (Donabedian 1992, Jun et al. 1998). According to O'Connor et al. (1994), 'It's the patient's perspective that increasingly is being viewed as a meaningful indicator of health services quality and may, in fact, represent the most important perspective',(cf. Andaleeb 2001, p. 32).

The extant literature shows that the dimensions of service quality vary according to the context, such as, two (e.g., Gronroos 1984), three (e.g., Brady and Cronin 2001, Rust and Oliver 1994), five (e.g., Parasuraman et al., 1988), and even ten (e.g., Parasuraman et al. 1985). As such, there is no standard agreement as to the number of dimensions of this concept (Brady and Cronin, 2001). However, most of the studies generally confirm that service quality should be multi dimensional (Grönroos 1984, 
Parasuraman et al. 1988), hierarchical (Brady and Cronin 2001; Rust and Oliver 1994), and context specific (Dagger et al. 2007).

\subsection{Satisfaction}

Satisfaction becomes an important cornerstone for service-oriented business practices around the world (Szymanski and Henard 2001). In healthcare, patient satisfaction is a major indicator in measuring the effects of quality or, overall service performance (Dagger et al. 2007, Saila et al. 2008). Satisfaction also leads to favourable results, such as higher rates of patient retention and higher profits (Zeithaml 2000). As such, customer (or, patient) satisfaction must be an integral part of health care organizations' strategic processes (Andaleeb 2001). Donabedian (1992) suggests that satisfaction should receive equal importance as service quality in order to design and manage the health care systems effectively.

Satisfaction is an 'affective response' (Giesh and Cote 2000) though scholars report this construct from different viewpoints, such as, a fulfillment response (Oliver 1997), an overall evaluation (Fornell 1992), psychological state (Howard and Sheth 1969), global evaluative judgment (Westbrook 1981) and summary attribute phenomenon (Oliver 1993). Whereas service quality is a cognitive construct, satisfaction is an attitudinal construct (e.g., Brady and Robertson 2001, Cronin and Taylor 1992, Gotlieb et al. 1994). Thus, the extant literature identifies satisfaction as an affective response to the cognitive service quality approach (Oliver 1997; Taylor and Baker 1994). This distinction suggests a casual model that identifies service quality as an antecedent to satisfaction (Choi et al. 2004). In health care settings, numerous studies support this causal linkage between service quality and satisfaction (Andaleeb 2001, Dagger et al. 2007, Woodside et al. 1989). Thus, given the important link between 
quality and satisfaction, this study models satisfaction as a function of perceived service quality in the context of mHealth:

\section{H1: Service quality has an impact on satisfaction in mHealth services.}

\subsection{Continuance Intentions}

The success of a technology mediated service platform, such as mHealth, depends a lot on the ongoing usage rather than initial acceptance (Bhattacherjee 2001, Limayem et al. 2007). As such, an increasing body of research in this domain depends on continuance theory (Akter et al. 2011). This study defines continuance as a usage stage when technology based service use (e.g., mHealth) transcends conscious behavior and becomes part of normal routine activity. Continuance decision is similar to consumers' repurchase decision, which is primarily based on satisfaction of a particular product or service (Anderson and Sullivan 1993, Oliver 1980, 1993). Bhattacherjee (2001, pp. 351352) highlights the importance of continuance in IT services by stating that "long-term viability of an IS and its eventual success depend on its continued use rather than [its] first-time use." Thus, continuance behavior is a highly relevant construct from a practical perspective because service usage obviously continues well beyond the initial adoption (Montoya et al. 2010).

The continuance theory posits that consumers' satisfaction with a service is the primary motivation for continuance intentions (e.g. Bhattacherjee et al. 2001). However, research is scant in exploring the impact of both service quality and satisfaction on continuance intentions. Dagger et al.'s work (2007) implies that both service quality and satisfaction influences one's inclination to continue using health services. Most health care platforms recognize these relationships because the level of continuance intentions indicates their overall financial performance or, economic viability (Bernhardt et al. 
2000, Eskildsen et al. 2003). Hence, this interest creates a need for developing a deeper understanding of the relationship between these constructs.

\section{H2: Customer satisfaction has an impact on continuance intentions.}

\section{H3: Service quality has an impact on continuance intentions.}

\subsection{Quality of life}

Quality of life refers to the well-being and happiness of an individual (Ferrans and Powers 1992). Quality-of-life perceptions, therefore, determine an individuals' evaluation of the life and the positive or negative attributes that characterize the life condition, including health status. Thus, this study views quality of life as a subjective, individual, and experiential concept. Given the healthcare context of the present study and the significance of healthcare as a vital component in quality of life, this study defines QOL as a sense of overall well being in health (Dagger and Sweeney 2006). Straub and Watson (2001) indicate that any technology based service platform should focus on increasing the quality of its users' lives. Researchers in both marketing (e.g. Dagger and Sweeney 2006) and information systems (e.g., Choi et al. 2007) report QOL as a critical outcome variable. Also, studies in the health care industry suggest exploring the impact of any new technology based service on QOL (Sirgy 2001). In this study, the QOL concept indicates that people have a variety of health care needs, and the more they satisfy these needs using mHealth services, the more they feel good about their quality of lives (Heisel and Flett 2005). Here, the study designates QOL as an alternative outcome variable and intends to explore how overall service quality and satisfaction contribute to quality of (health) life of an individual. However, no study yet frames the direct impact of overall service quality on QOL and indirect impact through 
satisfaction in mobile healthcare. Also, research is scant in measuring the critical impact of QOL on CI. Thus the study hypothesizes that:

H4: Satisfaction has an impact on quality of life.

H5: Service quality has an impact on quality of life.

H6: Quality of life has an impact on continuance intentions.

\subsection{Mediating effects of satisfaction}

Satisfaction is a major driver of positive QOL perception and continuance intentions, and, therefore, achieving high consumer satisfaction is a key goal of service dominant businesses (Oliver 1997, Bhattacherjee 2001, Chiou and Droge 2006). This study defines satisfaction as a mediator because, first, service quality (predictor) influences satisfaction (mediator); second, satisfaction influences CI \& QOL (criterion variables) and, finally, service quality influences the criterion variables in the absence of the mediator's influence (Barron and Kenney 1986). In addition, satisfaction as a mediator or an 'affective' attitude between 'cognitive beliefs' (e.g. service quality) and 'conative' constructs (e.g. CI and QOL) draws much attention in psychology (Ajzen and Fishbein 1980), marketing (Bansal et al. 2005, Dagger and Sweeney 2006) and information systems literature (Bhattacherjee 2001). Thus, the mediating role of satisfaction in the high-involvement mHealth services is important to explore:

H7: Satisfaction mediates the relationship between service quality and continuance intentions.

H8: Satisfaction mediates the relationship between service quality and QOL. 


\subsection{Moderating effects of service quality}

This study defines a moderator as "a variable that affects the direction and/or strength of the relation between an independent or predictor variable and a dependent or criterion variable" (Barron and Kenney 1986, p. 1174). In fact, moderation occurs when predictor (satisfaction) and moderator (service quality) have a joint effect in accounting for incremental variance in criterion variables (CI and QOL) beyond that explained by the main effects (Cohen and Cohen 1983). This study assumes service quality as a moderator which may have an influence on the links between satisfaction- CI and satisfaction - QOL. As such, the variation in service quality might influence the strength or the direction of these links (Barron and Kenney 1986). Surprisingly, research on the moderating role of service quality on both these associations is nonexistent. This study finds this omission intriguing in order to explore complex interdependencies among latent variables (Chin et al. 2003, Homburg and Giering 2001). Besides, an analysis of moderating effects is of high relevance as complex relationships are typically subject to contingencies in the causal network of consumer attitudes. Thus, the study hypothesizes that:

H9: Service quality moderates the relationship between satisfaction and continuance intentions.

H10: Service quality moderates the relationship between satisfaction and QOL.

\section{Methodology}




\subsection{Research Context}

This study focuses on mobile telemedicine services in Bangladesh, which is one of the leading mHealth service providing developing nations (Akter and Ray 2010). In recent years, this particular mHealth platform has become very popular in the developing world ( e.g., India, Bangladesh, Pakistan, Mexico, South Africa, Peru etc.) and serves millions by delivering right time medical services at an affordable cost (Ivatury et al. 2009, Akter et al. 2011). Currently, more than 24 million people in Bangladesh have access to such $\mathrm{B} 2 \mathrm{C}$ mHealth services provided by the leading mobile operator Grameen phone. Under this platform, a customer (or, a patient) can access health service at anytime by dialing ' $789^{\prime}$ ' from his/her own mobile phones and receive services in the form of medical information, consultation, treatment, diagnosis, referral, treatment and counselling from registered physicians. In addition, customers who do not have their own mobile phones can access this mHealth service from local mobile phone kiosks which are widely available at every corner of the country.

\subsection{Qualitative Research}

This study obtained qualitative data from 3 focus group discussions conducted with mHealth consumers in Bangladesh. A total of 24 participants, 8 per focus group, were involved in the focus group sessions. Participants ranged in age from 18 to 62 years and both genders had equal participation. Each session was conducted by two moderators which lasted about 90 minutes. In addition, ten in-depth interviews were conducted to explore users' insights on the research agenda. In both cases, participants were recruited using convenient sampling in order to ensure productive findings and the richest data for scale development (Dagger et al. 2007). In each case, respondents were asked to 
evaluate their mHealth experiences. The study asked the following questions to identify the service quality dimensions:

a. In your opinion, what makes mHealth different from other health services?

b. What are the major merits and demerits of mHealth services?

c. Any positive or negative experience that you had while receiving mHealth services?

The answers were recorded, synthesised and sorted into different categories to identify the core dimensions and their link to outcome constructs. In the qualitative study, service quality was frequently identified as a multidimensional and context specific concept. Users expressed their opinion on different service-level attributes (e.g., "I can access mHealth platform whenever I want" or, "The physician shows sincere interest to solve my problems," or, "I feel safe while consulting with Physicians" or, "It is worthwhile having service from this platform") under multiple dimensions. Throughout this process, the study found support for five primary service quality dimensions in mHealth, that is, convenience, confidence, cooperation, care and concern on privacy.

\subsection{Instrument Development}

The questionnaire consists of previously published multi-item scales with favourable psychometric properties and items from qualitative research (see Table 1). All the constructs in the model, except satisfaction, were measured using 7 point likert scale (e.g., strongly disagree - strongly agree). Satisfaction was measured using bi-polar semantic differential scale (e.g., very dissatisfied - very satisfied). The study developed 
the primary version of the questionnaire in English, and then translated the measures into the local language (Bangla). The local version was retranslated and confirmed by a panel of judges that both versions reflect the same content. Before the final study, the study conducted a pretest over 15 convenient samples to ensure that the question content, wording, sequence, format and layout, question difficulty, instructions and the range of the scales were appropriate. In response to the pretest, context specific adjustments were made to refine the final version of the questionnaire. 
Table 1: Operationalisation of constructs

\begin{tabular}{|c|c|c|}
\hline Constructs & Operational Definitions & Measures \\
\hline $\begin{array}{l}\text { Convenience } \\
\text { (Akter et al. } \\
2010)\end{array}$ & $\begin{array}{l}\text { The degree to which the } \\
\text { mHealth service platform } \\
\text { is available 'anytime' and } \\
\text { 'anywhere' basis. }\end{array}$ & $\begin{array}{l}\text { CV1. I can access to mHealth whenever I need. } \\
\text { CV2. I can access to mHealth wherever I need. } \\
\text { CV3. mHealth platform does not have long waiting } \\
\text { time. } \\
\text { CV4. mHealth platform is always available. }\end{array}$ \\
\hline $\begin{array}{l}\text { Confidence } \\
\text { ( Dagger et al. } \\
\text { 2007; } \\
\text { Parasuraman et } \\
\text { al.1988) }\end{array}$ & $\begin{array}{l}\text { The degree to which } \\
\text { mHealth service provider } \\
\text { has the ability to serve the } \\
\text { patients. }\end{array}$ & $\begin{array}{l}\text { CF1. Physicians at mHealth platform are competent } \\
\text { in providing services. } \\
\text { CF2. I feel safe while consulting with Physicians at } \\
\text { mHealth platform. } \\
\text { CF3. The behaviour of physicians at mHealth } \\
\text { platform instills confidence in me. } \\
\text { CF4. Physicians have the knowledge to answer my } \\
\text { questions. }\end{array}$ \\
\hline $\begin{array}{l}\text { Cooperation } \\
\text { (Dagger et al. } \\
\text { 2007; } \\
\text { Parasuraman et } \\
\text { al. 1988) }\end{array}$ & $\begin{array}{l}\text { The degree to which } \\
\text { mHealth service provider is } \\
\text { willing to help patients and } \\
\text { provide prompt service. }\end{array}$ & $\begin{array}{l}\text { CO1. Physicians at mHealth platform provide me } \\
\text { prompt service. } \\
\text { CO2: Physicians provide the service by a certain } \\
\text { time. } \\
\text { CO3. Physicians are never too busy to respond to my } \\
\text { requests. } \\
\text { CO4. Physicians are willing to help me. }\end{array}$ \\
\hline $\begin{array}{l}\text { Care } \\
\text { (Dagger et al. } \\
\text { 2007; } \\
\text { Parasuraman et } \\
\text { al. 1988) }\end{array}$ & $\begin{array}{l}\text { The degree to which } \\
\text { mHealth service provider } \\
\text { shows caring and } \\
\text { individualized attention to } \\
\text { patients. }\end{array}$ & $\begin{array}{l}\text { CA1. Physicians give me personal attention. } \\
\text { CA2. Physicians give me individual care. } \\
\text { CA3. Physicians understand my specific needs. } \\
\text { CA4. Physicians have my best interests at heart. }\end{array}$ \\
\hline $\begin{array}{l}\text { Concern on } \\
\text { Privacy } \\
\text { (Parasuraman et } \\
\text { al. 2005) }\end{array}$ & $\begin{array}{l}\text { The degree to which } \\
\text { mHealth service platform } \\
\text { reduces concerns by } \\
\text { maintaining patients' } \\
\text { privacy. }\end{array}$ & $\begin{array}{l}\text { CN1. mHealth platform protects information about } \\
\text { my personal problems. } \\
\text { CN2. mHealth platform does not share my personal } \\
\text { health information with others. } \\
\text { CN3. mHealth platform protects information about } \\
\text { my personal identity. } \\
\text { CN4. mHealth platform offers me a meaningful } \\
\text { guarantee that it will not share my information. }\end{array}$ \\
\hline $\begin{array}{l}\text { Continuance } \\
\text { Intention } \\
\text { (Bhattacherjee } \\
\text { 2001) }\end{array}$ & $\begin{array}{l}\text { Users' intention to continue } \\
\text { using mHealth services. }\end{array}$ & $\begin{array}{l}\text { CI1. I intend to continue using mHealth. } \\
\text { CI2. My intention is to continue using this service } \\
\text { rather than use any alternative means (e.g., going to } \\
\text { local clinics) } \\
\text { CI3. I will not discontinue my use of this service. }\end{array}$ \\
\hline $\begin{array}{l}\text { Satisfaction } \\
\text { (Spreng et } \\
\text { al.1996) }\end{array}$ & $\begin{array}{l}\text { Users' affect with (or, } \\
\text { feelings) about prior } \\
\text { mHealth services use. }\end{array}$ & $\begin{array}{l}\text { How do you feel about your overall experience of } \\
\text { mHealth service use: } \\
\text { SA1. Very dissatisfied / very satisfied } \\
\text { SA2. Very frustrated / very contended. } \\
\text { SA3. Very displeased / very pleased } \\
\text { SA4. Absolutely terrible / absolutely delighted }\end{array}$ \\
\hline $\begin{array}{l}\text { Quality of life } \\
\text { (Dagger \& } \\
\text { Sweeney } \\
\text { 2006; Choi et al. } \\
\text { 2007) }\end{array}$ & $\begin{array}{l}\text { QOL refers to a sense of } \\
\text { overall well being in } \\
\text { health. }\end{array}$ & $\begin{array}{l}\text { QOL1. Getting services from this platform have } \\
\text { enabled me to improve my overall health. } \\
\text { QOL2. In most ways, my life has come closer to my } \\
\text { ideal since I started using this service. } \\
\text { QOL3. The conditions of my health life have } \\
\text { improved because of this service. } \\
\text { QOL4. I have been more satisfied with my health life, } \\
\text { thanks to this service. } \\
\text { QOL5. So far, this service has helped me to achieve } \\
\text { the level of health I most want in life. }\end{array}$ \\
\hline
\end{tabular}




\subsection{Sampling}

Data were collected from Bangladesh under a global mHealth assessment project from January 07 to March 17, 2010. In the absence of lists for drawing a random sample, about six hundred interviews were planned from two urban areas and three rural areas using area wise cluster sampling. Areas were selected in a manner such that different socioeconomic groups were represented. From each area, firstly, thanas were selected randomly; then, streets/villages were selected from each thana; and finally, residential homes were selected from each street/village. In order to obtain a probability sample, systematic random sampling was applied so that each sample unit/element had an equal chance of being selected. The population was defined as the customers who had experience of using mobile telemedicine services in the past 12 months. In all survey interactions, interviewers were given a letter of introduction from a reputed university containing the phone number for respondents to see that the study was authentic. Those who agreed to be interviewed were explained the academic purpose of the study with adequate assurance of anonymity and freedom of not answering particular questions or withdrawing from the interview at any stage. A total of 623 respondents were approached, of which $480(77 \%)$ surveys were ultimately completed. Of the total number of completed surveys, seven were considered problematic and excluded, because of excessive missing data, don't know answers, or N/A answers, and response biases. Finally, 473 surveys were analyzed.

The demographic profile of the respondents represents a diverse cross section of the population (see Table 2). The respondent group ranged in age from 18 to 62, were 59 percent male, 58 percent lived in rural areas, 47 percent had income less than US $\$ 70$ per month, employed in a wide range of professions (students, professionals, self- 
employed, academics, farmers, housewives, day laborers, retirees), and had various educational levels (from illiterate to doctoral degrees).

\begin{tabular}{|c|c|c|c|c|c|}
\hline \multicolumn{6}{|c|}{ Table 2: Demographic profile of respondents } \\
\hline Items & Categories & $\%$ & Items & Categories & $\%$ \\
\hline Gender & $\begin{array}{l}\text { Male } \\
\text { Female }\end{array}$ & $\begin{array}{l}59 \\
41 \\
\end{array}$ & Age & $\begin{array}{l}18-25 \\
26-33\end{array}$ & $\begin{array}{l}25 \\
32\end{array}$ \\
\hline Location & $\begin{array}{l}\text { Urban } \\
\text { Rural }\end{array}$ & $\begin{array}{l}42 \\
58\end{array}$ & & $\begin{array}{l}42-49 \\
50+\end{array}$ & $\begin{array}{l}17 \\
5\end{array}$ \\
\hline $\begin{array}{l}\text { Income } \\
\text { (per month } \\
\text { in US \$) }\end{array}$ & $\begin{array}{l}<\$ 70 \\
\$ 71-\$ 141 \\
\$ 142-\$ 212 \\
\$ 212+\end{array}$ & $\begin{array}{l}47 \\
22 \\
10 \\
21\end{array}$ & Occupation & $\begin{array}{l}\text { Working full time } \\
\text { Working part time } \\
\text { Housewife } \\
\text { Others }\end{array}$ & $\begin{array}{l}38 \\
34 \\
16 \\
12\end{array}$ \\
\hline
\end{tabular}

\subsection{Data Analysis}

Service quality in this study serves as a second-order reflective construct which contains convenience, confidence, cooperation, care and concern as the first-order components. According to Bagozzi (2010, p. 209), “The second-order factor approach is most valid and conceptually meaningful when the first-order factors loading on the second-order factor can be interpreted as subdimensions or components of a more abstract, singular construct". In the similar spirit, this study estimates the second-order mHealth service quality construct model applying the component-based structural equation modelling (SEM) or, partial least squares (PLS) path modelling technique. The PLS approach to SEM, also known as PLS Path Modeling (PLS-PM) is regarded as a component based SEM (Chin et al. 2003; Tenenhaus 2008) to model multiple causes and multiple indicators of a single latent variable, and to latent path models (Wold 1975, 1982, 1985). In contrast to covariance based SEM ( maximum likelihood approach), PLS path modeling is a favorable technique for estimating hierarchical models with moderating and mediating effects because it can ensure more theoretical parsimony and less model 
complexity (Chin 2010; Edwards 2001; Law et al. 1998; MacKenzie et al. 2005; Wetzels et al. 2009).

\subsubsection{Justification of the analytical approach}

This study applies component-based SEM (or, PLS) because, first, this approach is consistent with the objective of the study, which aims to develop and test a theoretical model through explaining and prediction (Chin 2010, Hair et al. 2011). Second, this approach estimates a hierarchical model with more theoretical parsimony and less model complexity (Bagozzi and Yi 1994, Edwards 2001, Wetzels et al. 2009). Third, this approach can effectively handle various constraints with regard to the distributional properties (multivariate normality), measurement level, sample size, model complexity, identification, and factor indeterminacy (Chin 1998b, 2010, Fornell and Bookstein 1982, Hair et al. 2011, Hulland 2010). Fourth, this approach works better when the

model is relatively complex (e.g., hierarchical model) and the phenomenon under study is new or changing (Chin and Newsted 1999). Finally, this approach is suitable for the study because PLS path modelling provides more accurate estimates of mediating and moderating effects by accounting for the measurement error that attenuates the estimated relationships and improves the validation of theories (Chin et al. 2003).

\subsubsection{Operationalisation of the approach}

This study applies PLS path modelling using PLS Graph 3.0 (Chin 2001) to estimate the reflective, second-order service quality model through the repeated use of manifest variables (Wold 1985). As per the guidelines of hierarchical modelling (Chin 2010; Wetzels et al. 2009), manifest variables were used repeatedly to estimate the scores of first-order constructs (i.e., convenience, confidence, cooperation, care and concern) as 
well as for the second-order service quality construct (See Appendix 1 for details). According to Wetzels et al. (2009), "This approach also allows us to derive the (indirect) effects of lower-order constructs, or dimensions, on outcomes of the higherorder construct." Using this approach, this study created the second-order service quality construct that represents all the manifest variables of the underlying first-order latent variables (convenience, confidence, cooperation, care and concern). Table 3 outlines the equation for estimating the second-order, reflective, service quality construct model in mHealth. For instance, the equation for the first-order model specifies first-order latent variable $\left(\eta_{j}\right)$, its indicators $\left(y_{i}\right)$, loadings $\left(\Lambda_{y}\right)$ and an error term $\left(\varepsilon_{i}\right)$. The equation of the second-order model specifies the first-order factors $\left(\eta_{j}\right)$ in terms of the second-order latent variables $\left(\xi_{k}\right)$ and error $\left(\zeta_{j}\right)$ for the first-order factor and second-order latent variables loadings $(\Gamma)$. Therefore, applying this equation, the study estimates the research model and presents empirical findings in the next section.

\begin{tabular}{|c|c|}
\hline \multicolumn{2}{|c|}{ Table 3: Estimation of mHealth service quality as a second-order, reflective Model } \\
\hline \multicolumn{1}{|c|}{ First Order model } & \multicolumn{1}{c|}{$\begin{array}{c}\text { Second order model } \\
\text { (mHealth Service quality construct) }\end{array}$} \\
\hline$y_{i}=\Lambda_{y} \cdot \eta_{j}+\varepsilon_{i}$ & $\eta_{j}=\Gamma \cdot \xi_{k}+\zeta_{j}$ \\
$y_{i}=$ manifest variables (e.g., items/ indicators) & $\eta_{j}=$ first order factors (e.g., convenience) \\
$\Lambda_{y}=$ loadings of first order latent variable & $\Gamma=$ loadings of second order latent variable \\
$\eta_{j}=$ first order latent variable (e.g., convenience, & $\xi_{k}=$ second order latent variable (e.g., mHealth \\
confidence, cooperation, care and concern) & service quality) \\
$\varepsilon_{i}=$ measurement error of manifest variables & $\zeta_{j}=$ measurement error of first order factors \\
\hline
\end{tabular}




\section{Findings}

\subsection{Assessment of the first order model}

The study assesses the psychometric properties of the first-order measurement model by examining reliability, convergent validity and discriminant validity. The first-order model consists of 8 constructs in the research model, that is, convenience, confidence, cooperation, care, concern, satisfaction, continuance intentions and quality of life. Initially, the study calculated all the item loadings which exceed the cut-off values of 0.7 and significant at $\mathrm{p}<0.001$. The higher average of item loadings $(>0.7)$ and a narrower range of difference provide strong evidence that respective items have greater convergence in measuring the underlying construct (Chin 2010). As such, the study removed $\mathrm{CV} 3, \mathrm{CF} 4, \mathrm{CO} 2, \mathrm{CA} 1, \mathrm{CN} 4, \mathrm{QOL} 2$ and QOL5 as their item loadings were lower than 0.7 (see Table 1 for the complete list of items).

A complete picture of the first order model emerges in Table 4 after applying the testing criteria of item loadings and eliminating the items that damage the soundness of the criteria. The study also calculated average variance extracted (AVE) and composite reliability (CR) (Chin 1998a; Fornell \& Larcker 1981) to confirm reliability of all the measurement scales. AVE measures the amount of variance that a construct captures from its indicators relative to measurement error, whereas CR is a measure of internal consistency (Chin 2010). Basically, these two tests indicate the extent of association between a construct and its indicators. The study shows that the CR and AVE of all scales are either equal to or exceed respectively 0.80 and 0.50 cut-off values (Fornell \& Larcker 1981). Thus, the study confirmed that all the item loadings, CRs and AVEs exceed their respective cut off values and ensure adequate reliability and convergent validity (Chin 1998a; Fornell \& Larcker 1981). 
In addition, in Table 5, this study calculates the square root of the AVE that exceeds the intercorrelations of the construct with the other constructs in the model to ensure discriminant validity (Fornell \& Larcker, 1981). This test indicates that the constructs do not share the same type of items and they are conceptually distinct from each other (Chin 2010). In other words, each construct and its measures in the research model do a great job in discriminating themselves from other constructs and their corresponding measures. Thus, the study ensures a valid measurement model with the evidence of adequate reliability, convergent validity, and discriminant validity. This process also paves the way for testing all the hypotheses and proving the research model.

\begin{tabular}{|c|c|c|c|c|}
\hline \multicolumn{5}{|c|}{ Table 4: Psychometric Properties of the first order constructs } \\
\hline Constructs & Items & Loadings & $\begin{array}{l}\text { Composite } \\
\text { Reliability (CR) }\end{array}$ & $\begin{array}{l}\text { Average Variance } \\
\text { Extracted (AVE) }\end{array}$ \\
\hline Convenience & $\begin{array}{l}\text { CV1 } \\
\text { CV2 } \\
\text { CV4 }\end{array}$ & $\begin{array}{l}0.82 \\
0.81 \\
0.83\end{array}$ & 0.86 & 0.67 \\
\hline Confidence & $\begin{array}{l}\text { CF1 } \\
\text { CF2 } \\
\text { CF3 }\end{array}$ & $\begin{array}{l}0.90 \\
0.86 \\
0.81\end{array}$ & 0.89 & 0.73 \\
\hline Cooperation & $\begin{array}{l}\mathrm{CO} 1 \\
\mathrm{CO} 3 \\
\mathrm{CO} 4\end{array}$ & $\begin{array}{l}0.95 \\
0.94 \\
0.93\end{array}$ & 0.96 & 0.89 \\
\hline Care & $\begin{array}{l}\text { CA2 } \\
\text { CA3 } \\
\text { CA4 }\end{array}$ & $\begin{array}{l}0.93 \\
0.92 \\
0.86\end{array}$ & 0.93 & 0.82 \\
\hline Concern on Privacy & $\begin{array}{l}\mathrm{CN} 1 \\
\mathrm{CN} 2 \\
\mathrm{CN} 3\end{array}$ & $\begin{array}{l}0.90 \\
0.94 \\
0.95\end{array}$ & 0.95 & 0.87 \\
\hline Satisfaction & $\begin{array}{l}\text { SA1 } \\
\text { SA2 } \\
\text { SA3 } \\
\text { SA4 }\end{array}$ & $\begin{array}{l}0.95 \\
0.94 \\
0.94 \\
0.93\end{array}$ & 0.94 & 0.89 \\
\hline Continuance Intentions & $\begin{array}{l}\text { CI1 } \\
\text { CI2 } \\
\text { CI3 }\end{array}$ & $\begin{array}{l}0.93 \\
0.91 \\
0.95\end{array}$ & 0.95 & 0.86 \\
\hline QOL (Quality of Life) & $\begin{array}{l}\text { QOL1 } \\
\text { QOL3 } \\
\text { QOL4 }\end{array}$ & $\begin{array}{l}0.91 \\
0.93 \\
0.90\end{array}$ & 0.95 & 0.83 \\
\hline
\end{tabular}


Table 5 : Mean, Standard Deviation (SD) and Correlations of the Latent Variables

\begin{tabular}{|l|l|l|l|l|l|l|l|l|l|l|}
\hline Construct & Mean & SD & CV & CF & CO & $C A$ & $C N$ & SA & CI & QOL \\
\hline Convenience (CV) & 5.78 & 0.98 & $0.82^{*}$ & & & & & & & \\
\hline Confidence (CF) & 5.75 & 1.12 & 0.69 & $0.86^{*}$ & & & & & & \\
\hline Cooperation (CO) & 5.64 & 1.18 & 0.73 & 0.65 & $0.94^{*}$ & & & & & \\
\hline Care (CA) & 5.74 & 1.17 & 0.64 & 0.72 & 0.57 & $0.90^{*}$ & & & & \\
\hline Concern (CN) & 5.75 & 1.18 & 0.47 & 0.44 & 0.44 & 0.42 & $0.93^{*}$ & & & \\
\hline Satisfaction (SA) & 5.68 & 1.11 & 0.68 & 0.66 & 0.64 & 0.58 & 0.49 & $0.95^{*}$ & & \\
\hline Continuance (CI) & 5.59 & 1.26 & 0.65 & 0.58 & 0.63 & 0.53 & 0.43 & 0.70 & $0.92^{*}$ & \\
\hline Quality of life (QOL) & 5.53 & 1.14 & 0.68 & 0.67 & 0.62 & 0.60 & 0.51 & 0.72 & 0.70 & $0.91^{*}$ \\
\hline *square root of the AVE on the diagonal & & & & & & & \\
\hline
\end{tabular}

\subsection{Assessment of the second-order Model}

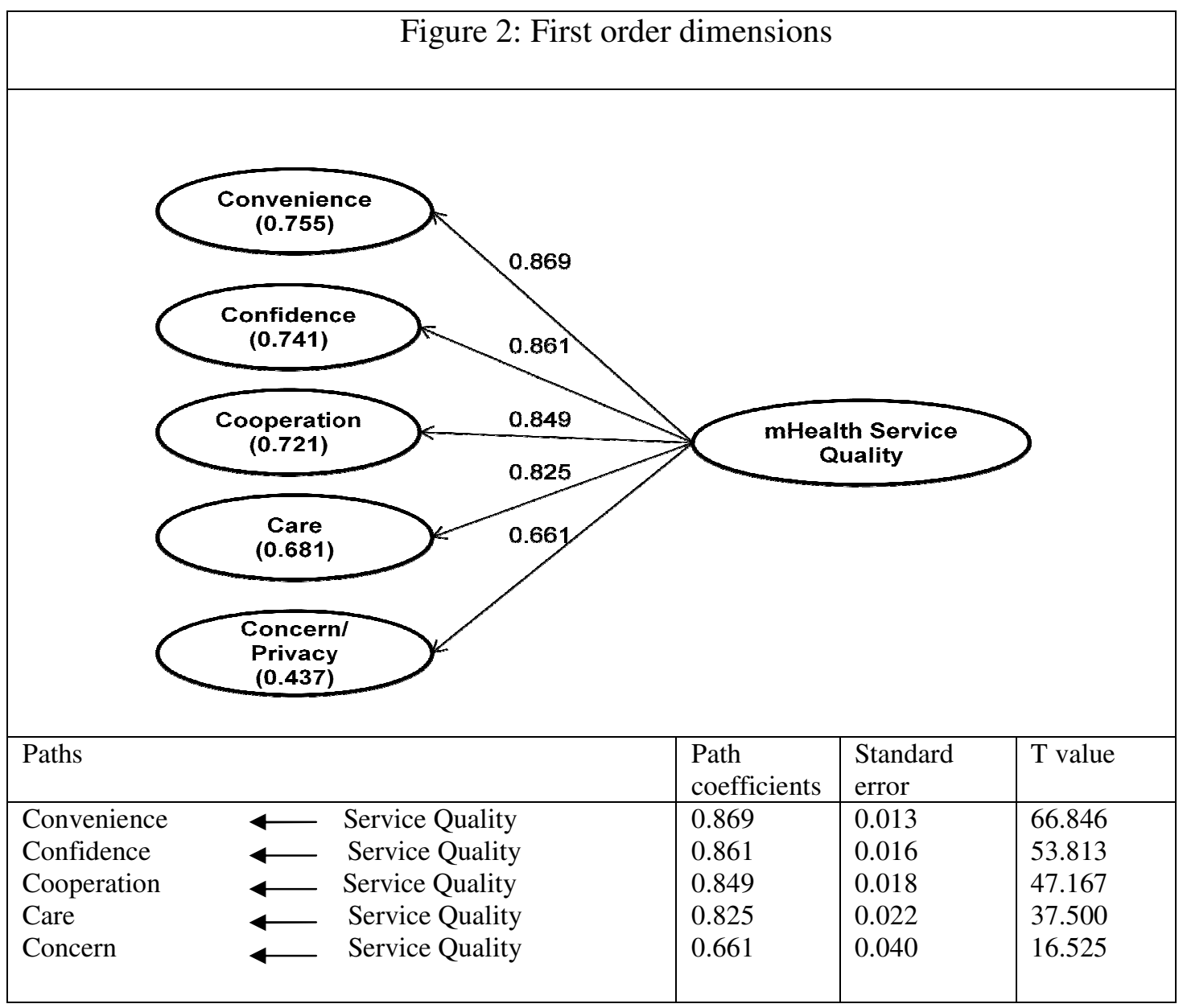


This study also estimates the second-order, reflective service quality construct, which consists of five first-order components (convenience, confidence, cooperation, care and concern), representing $15(3 \times 5)$ items. The CR and the AVE of the second order service quality construct are respectively 0.943 and 0.524 , providing evidence of reliable, higher order measures. The results indicate that service quality gets its meaning indirectly through the measures of five first order components (see Figure 2). The results also confirm that the hierarchical service quality construct has a significant association $(\mathrm{P}<0.001)$ with all the primary components, that is, convenience $(\beta=$ $0.869)$, confidence $(\beta=0.861)$, cooperation $(\beta=0.849)$, care $(\beta=0.825)$ and concern $(\beta$ $=0.661)$. The study analyzes the implications of these results in the discussion section.

\subsection{Structural Model}

In order to assess the research model, this study estimates the impact of overall mHealth service quality on satisfaction, continuance and quality of life (Figure 3A). Initially, the study estimates the service quality-satisfaction-continuance link and the results give a standardized beta of 0.753 from service quality to satisfaction, 0.315 from satisfaction to continuance and 0.231 from service quality to continuance intentions. Based on these findings, this study confirms that overall service quality has both direct and indirect impact on continuance intentions, which prove $\mathrm{H} 1, \mathrm{H} 2$ and $\mathrm{H} 3$. 


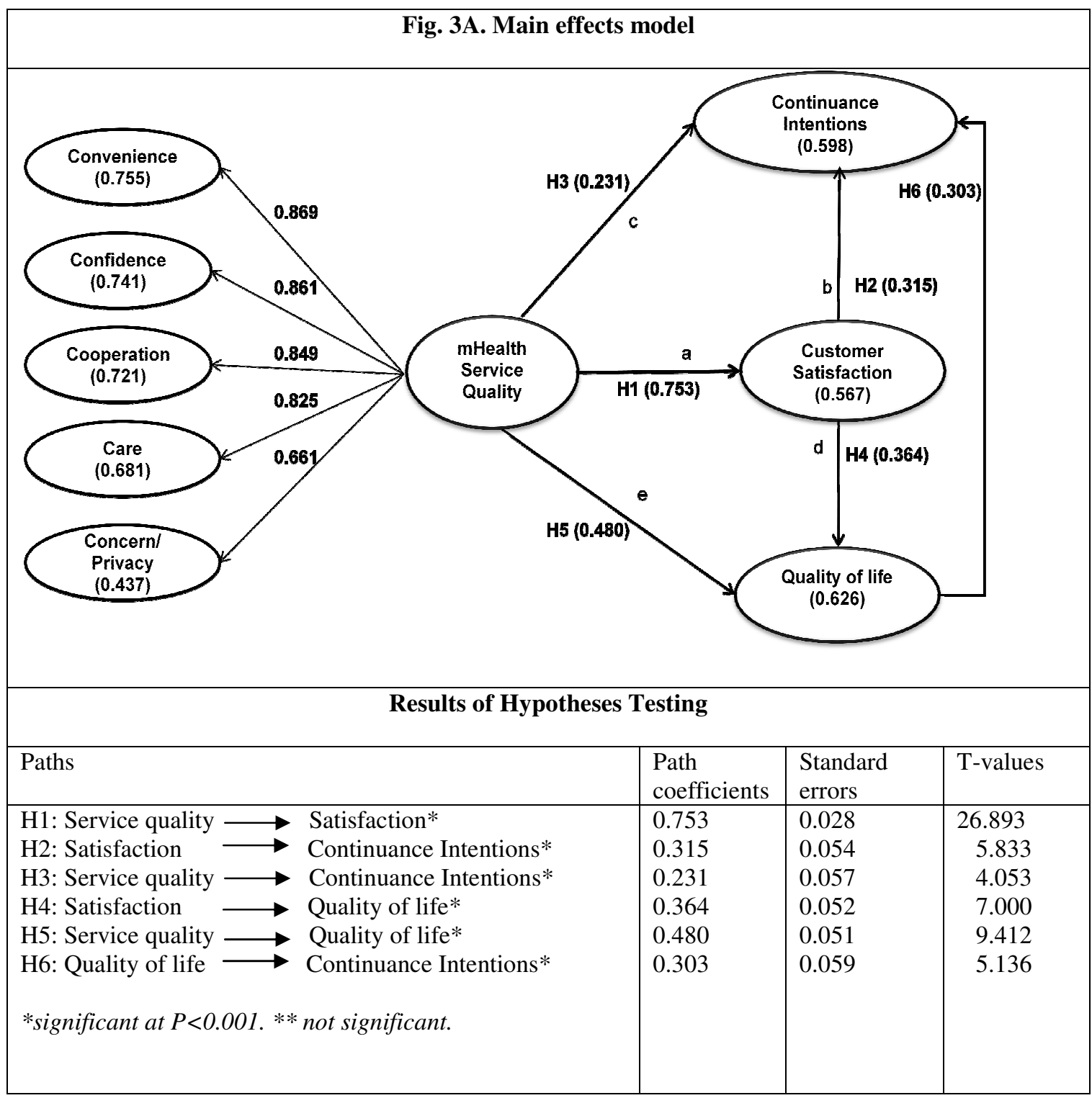

Furthermore, the study estimates the service quality-satisfaction-QOL link and the results give a standardized beta of 0.364 from satisfaction to QOL and 0.480 from service quality to QOL. These results again confirm the direct and indirect impact of service quality on QOL, thereby proving H4 \& H5 respectively. This study also assesses the impact of QOL on continuance intentions (path $=0.303$ ), which confirms H6. Overall, the variance explained by the mHealth service quality model in terms of $\mathrm{R}^{2}$ is 0.567 for customer satisfaction, 0.598 for continuance intentions and 0.626 for 
QOL, which are significantly large $\left(f^{2}>0.35\right)$ according to the effect sizes defined for $R^{2}$ by Cohen (1988).

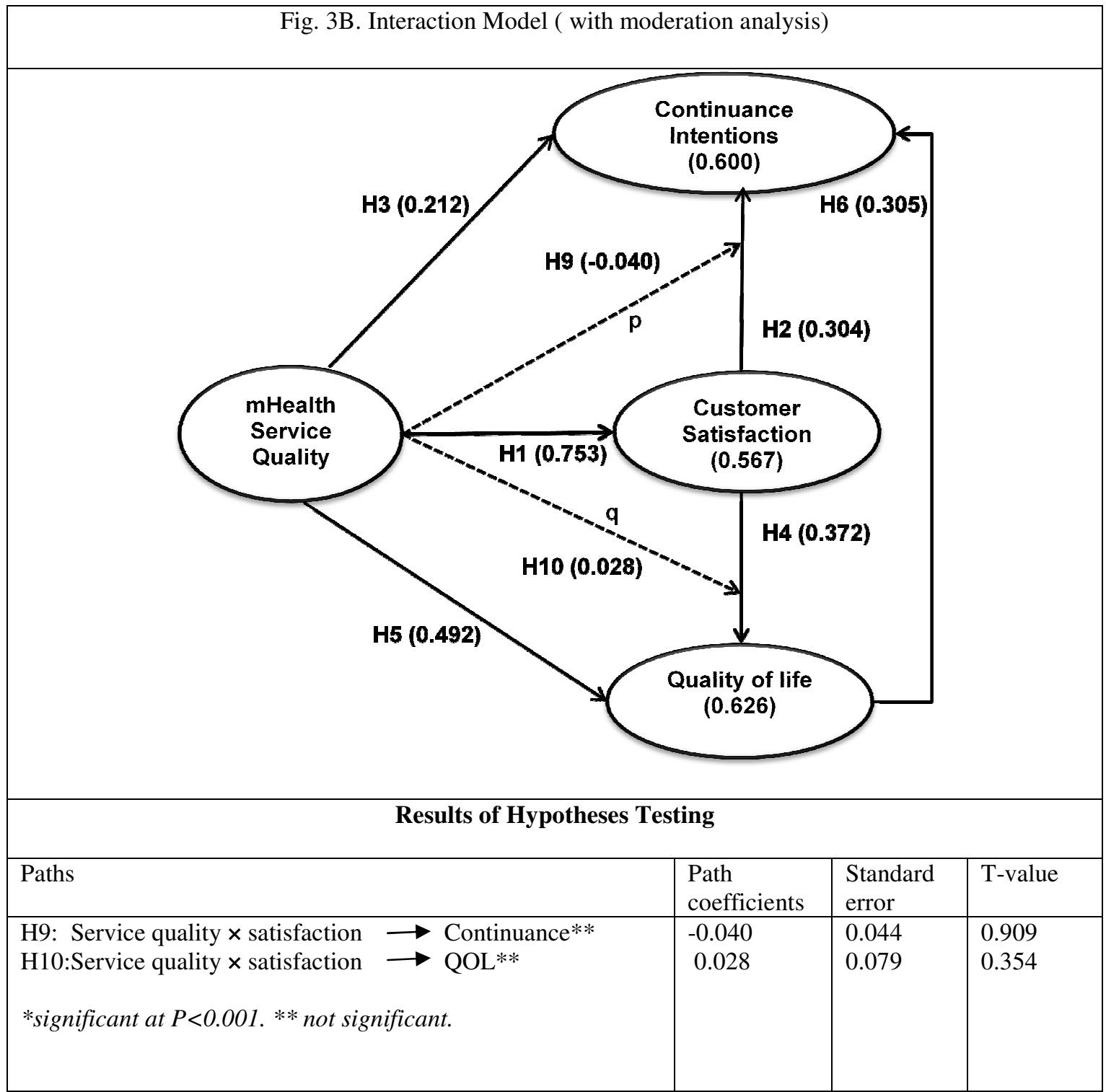

\subsubsection{Mediation Analysis}

In Figure 3A, this study analyzes the mediating effect of satisfaction on both SQ-CI link and SQ-QOL link. Before analysis, the study adequately confirms the criteria for mediation analysis (Barron and Kenney 1986) as follows, first, the predictor (SQ) influences the mediator (satisfaction). Second, the mediator (satisfaction) influences the criterion variables (CI \& QOL). Third, the predictor (SQ) influences the criterion 
variables (CI \& QOL) in the absence of the mediator's influence. In Figure 3A, 'a' refers to the SQ-SAT path, 'b' refers to the SAT-CI path, 'c' refers to the SQ-CI path, 'd' refers to the SAT-QOL path and 'e' refers to the SQ-QOL path. Thus, to establish the mediating effect of satisfaction, the indirect effect of $a \times b$ has to be significant for SQ - CI link and $\mathrm{a} \times \mathrm{d}$ has to be significant for SQ-QOL link (Iacobucci, 2008). Here, If the $z$-value exceeds 1.96 ( $p<0.05$ ), the study can accept $\mathrm{H} 7 \& \mathrm{H} 8$, because the results indicate that overall service quality has an indirect impact on on both CI and QOL through satisfaction (Sobel 1982). The study estimates the $\mathrm{z}$ value as follows (see Fig. 3A):

$$
\begin{aligned}
& Z_{\text {SQ-CI link }}=\frac{a \times b}{\sqrt{b^{2} \times s_{a}^{2}+a^{2} \times s_{b}^{2}+s_{a}^{2} \times s_{b}^{2}}} \\
& Z_{\text {SQ-QOL link }}=\frac{a \times d}{\sqrt{d^{2} \times s_{a}^{2}+a^{2} \times s_{d}^{2}+s_{a}^{2} \times s_{d}^{2}}}
\end{aligned}
$$

The $z$ value for SQ-CI link is 5.70 and for SQ-QOL link is 6.77, which supports the mediating effects of satisfaction. These findings support $\mathrm{H} 7 \& \mathrm{H} 8$, which imply that service quality has an indirect impact on CI \& QOL. To estimate size of the indirect effect, this study uses the VAF (Variance Accounted For) value which represents the ratio of the indirect effect to the total effect. The results indicate that indirect effects (or, customer satisfaction) explain about $51 \%$ of the total effect of service quality on continuance intentions and about $36 \%$ of the total effect of service quality on QOL.

$$
\begin{gathered}
\mathrm{VAF}_{\text {SQ-CI link }}=\frac{a \times b}{a \times b+\mathrm{c}}=\frac{0.753 \times 0.315}{0.753 \times 0.315+0.231}=0.506 \\
\mathrm{VAF}_{\text {SQ-QOL link }}=\frac{a \times d}{a \times d+\mathrm{e}}=\frac{0.753 \times 0.364}{0.753 \times 0.364+0.480}=0.363
\end{gathered}
$$




\subsubsection{Moderation Analysis}

In Figure 3B, this study presents the moderation analysis applying PLS productindicator approach (Chin et al. 2003) to detect the moderating effect of service quality on the relationship between satisfaction-CI and satisfaction-QOL. To test the moderating effects, first, this study multiplies satisfaction (predictor) and service quality (moderator) to create an interaction construct that predicts both CI and QOL respectively. In this study, satisfaction is a simple latent construct representing 4 items, service quality is a second order construct representing 15 items, thus, the interaction construct represents $60(4 \times 15)$ items. Second, this study estimates the influence of the predictor (satisfaction) on the criterion variables (CI \& QOL), the direct effect of moderator (SQ) on the criterion variables and the influence of the interaction variable (satisfaction $\times$ service quality) on the criterion variables (Figure 3B). Now, the study can confirm the significance of the moderator (service quality) if the interaction effects (path p \& q) are meaningful, independent of the size of the other path coefficients (Chin et al. 2003). In Figure 3B, this study estimates the standardized path coefficients of 0.040 and 0.028 to predict the impact of interaction construct on both CI (p) and QOL (q). The results indicate that these interaction effects are not significant at $p<0.05$. The sizes of the interaction effects are as follows:

$$
\begin{gathered}
f^{2}{ }_{C I}=\frac{R_{i}{ }^{2}-R_{m}^{2}}{1-R_{i}^{2}}=\frac{0.600-0.598}{1-0.600}=0.005 \\
f^{2}{ }_{Q O L}=\frac{R_{i}^{2}-R_{m}^{2}}{1-R_{i}^{2}}=\frac{0.626-0.626}{1-0.626}=0.000
\end{gathered}
$$

(Here, $i=$ interaction model, $m=$ main effects model)

The results show that the sizes of the interaction effects are small $\left(f^{2}<0.02\right)$ (Cohen, 1988) as well as the resulting beta changes $(\mathrm{p}=-0.040, \mathrm{q}=0.028)$ are insignificant $(\mathrm{P}<0.05)$ (Chin et al. 2003). As such, the study confirms that service 
quality does not have any moderating impact on the relationship between satisfaction-CI and satisfaction-QOL. Thus, the study rejects H9 and H10 (see Fig. 3B).

\subsection{Model Evaluation: Structural Model Results}

In order to assess the validity of PLS based research model, first, this study estimates the power $(1-\beta)$ of the model in order to assess its ability to reject a false null hypothesis $\left(\mathrm{H}_{0}\right)($ Cohen 1988). In other words, statistical power assesses the probability of finding significant associations among the latent variables when true relationships exist (Baroudi and Orlikowski 1988). In this study, the power of the main effects model is 0.99 which compellingly exceeds the 0.80 cut off value. This high power $(>0.80)$ indicates that the results of hypotheses testing are valid and the relationships are significant. Second, this study estimates the predictive relevance $\left(\mathrm{Q}^{2}\right)$ of the endogenous constructs by using sample reuse technique based on blindfolding procedure (Stone 1974, Geisser 1975). $Q^{2}$ indicates how well observed values are reproduced by the model and its parameter estimates. Using the omission distance of 7 under a cross validated communality approach, this study obtains $\mathrm{Q}^{2}$ of 0.68 for continuance intentions $(>0.50)$ and 0.79 for quality of life $(>0.50)$, which are indicative of a highly predictive model (Chin 2010). Finally, this study estimates the global fit measure (GoF) to assess the global validity of PLS based research model (Tenenhaus et al. 2005). GoF

refers to the geometric mean of the average communality and average $\mathrm{R}^{2}$ for all endogenous constructs. The GoF value ensures global validation of PLS models range between small $(\mathrm{GoF}=0.1)$, medium $(\mathrm{GoF}=0.25)$ and large $(\mathrm{GoF}=0.36)$. This study obtains a GoF value of 0.723 for the complete model, which exceeds the cut-off value of 0.36 for the large effect size (Cohen 1988). Thus, GoF allows us to conclude that the model has a better prediction power which adequately validates the PLS model globally (Wetzels et al. 2009). 


\section{Discussion}

\subsection{Summary of Findings}

The main thrust of this study is to model the impact of mHealth service quality on satisfaction, continuance intentions and quality of life. As such, the study develops a second order service quality model on five primary dimensions (i.e., convenience, confidence, cooperation, care and concern). The study also confirms the impact of overall service quality on satisfaction, continuance intentions and QOL. Since the development and operationalization of a reliable and valid model is a fundamental goal of scientific endeavor, the findings of the study make an important contribution to theory and practice.

In particular, the findings suggest that all the primary service quality dimensions have a significant positive association with overall service quality. Among these dimensions, 'convenience' emerges as the strongest component, suggesting that patients must have instant access to this healthcare delivery platform. In fact, this factor highlights the right time availability of this platform so that anyone can receive health services at anytime from anywhere. In the context of a low resource setting, this ubiquity is a central element in the promise of mHealth to transform the healthcare delivery system (Akter \& Ray 2010). Then the study identifies 'confidence' as a key component of overall service quality, suggesting that the behaviours of the provider must establish confidence among the patients. This finding is consistent with other service quality studies, indicating that more assurance from physicians can improve the level of overall quality perception (Andaleeb 2001). Then, 'cooperation' and 'care' emerge as significant components of overall service quality. Though the magnitudes of their effects are smaller than the effects of other dimensions, they should receive equal importance to improve the perception of overall service quality. Cooperation suggests 
that health professionals must provide prompt service and be available always and care indicates that they must understand the diversified needs of the patients and be caring and helpful. Finally, 'privacy related concerns' emerge as a significant component of service quality, suggesting that adequate protection of patients' information can lead to greater gains in patient satisfaction and continuance intentions.

The study confirms that overall service quality (SQ) is a significant predictor of satisfaction (explaining 57\% of variance), continuance intentions (explaining $60 \%$ of variance) and quality of life (explaining 63\% variance). This finding is consistent with the service dominant logic (Vargo and Lusch 2004), which implies that exchange process in business should focus on economic (i.e., continuance) and social outcomes (i.e., QOL). The findings also confirm that satisfaction is the key mediator between SQCI and SQ-QOL. Because satisfaction is a stronger predictor of CI and QOL relative to service quality, dissatisfied patients may discontinue this service, despite having positive perceptions of overall service quality. In other words, satisfaction is the necessary condition for CI \& QOL and for this reason the moderating effects of SQ are not significant in the relationship between satisfaction-CI and satisfaction-QOL. Overall, these findings suggest that mHealth service providers should consider 'satisfaction' as an important strategic objective to predict the impact of overall service quality on continuance intentions and quality of life.

\subsection{Contribution to Theory and Practice}

The mHealth service context emerges as an example of business and technology alignment in transformative services research, which aims to create uplifting changes of both individuals and communities through continued consumption. Since transformative service (e.g., mHealth) is a new area in IT service research, scholars still strive to frame its impact on critical service outcomes. Research is scant in this sector in terms of 
quality model and its impact on economic and social outcomes. Thus, this study extends the scope of IT service research by developing an mHealth service quality model on five dimensions (Convenience, confidence, cooperation, care and concern) and framing its overall impact on satisfaction, continuance intentions (economic outcome) and quality of life (social outcome).

The implications of this research are highly relevant to practitioners. For managers of mHealth services, the findings of the study improve an overall understanding of how customers evaluate mHealth service quality. In particular, the findings suggest that managers should focus on improving five service quality dimensions (convenience, confidence, cooperation, care and privacy) in order to have a positive impact on ultimate service outcomes. These findings also make it clear that increased service satisfaction provides a way for managers to ensure positive continuance intentions and quality of life. As continuance affects profitability and QOL influences social outcome, gaining insights on these behaviours is of critical importance to mHealth service providers. Thus, the findings of the study can help managers achieve patronage for firms, better health outcomes for patients and above all, an improved quality of life for the community.

\subsection{Limitations and Future Research Directions}

This study has several limitations. First, the context of the study is single provider, single country based. Future research could examine the sensitivity of the findings over multiple service providers in a cross country setting. There is always a difference with regard to the demographic variables. Information on these differences across cultures might be of considerable interest and significance to both researchers and practitioners for critical managerial decision making (Reynolds \& Smith 2010). Second, the study is based on cross sectional design, which contains typical limitations associated with this 
kind of research methodology. Future studies could undertake longitudinal study to unfold the impact of service quality on outcome constructs over time. Future studies could also explore the impact of contextual factors, such as, demographic variables (income, education, gender etc.) and situational constructs (usage frequency, cost etc.) on the research model.

\section{Conclusions}

The study seeks to model the impact of service quality on critical service outcomes in a transformative IT service research, directly applicable to B2C mHealth study. The findings of the study support the research model, thus lending confidence to the critical role of quality as a key decision-making variable to predict satisfaction, continuance intentions and quality of life in an emerging healthcare paradigm. The findings suggest that quality and associated economic and social outcomes should be mandatory in studies of IT service research. Aligned with the findings, Ostrom et al. (2010) state, "Service is not only about increasing revenues and profits at for-profit firms but also about how to advance service in a way that delivers higher-order, societal outcomes."

\section{Acknowledgments}

The authors appreciate and gratefully acknowledge the financial support provided for the field study by the Asia Pacific Ubiquitous Healthcare Research Centre (APuHC), Australia. Comments by Wynne W. Chin of University of Houston and James Nelson of University of Colorado at Boulder were helpful in revising the paper. The authors also thank data collection team members of WHO global mHealth assessment project (Bangladesh Chapter) comprising Benzir Shaon, Saida Mona, Waheduzzaman Adnan, Ismat Ara and Shafayet Ullah for their invaluable help. 
Appendix

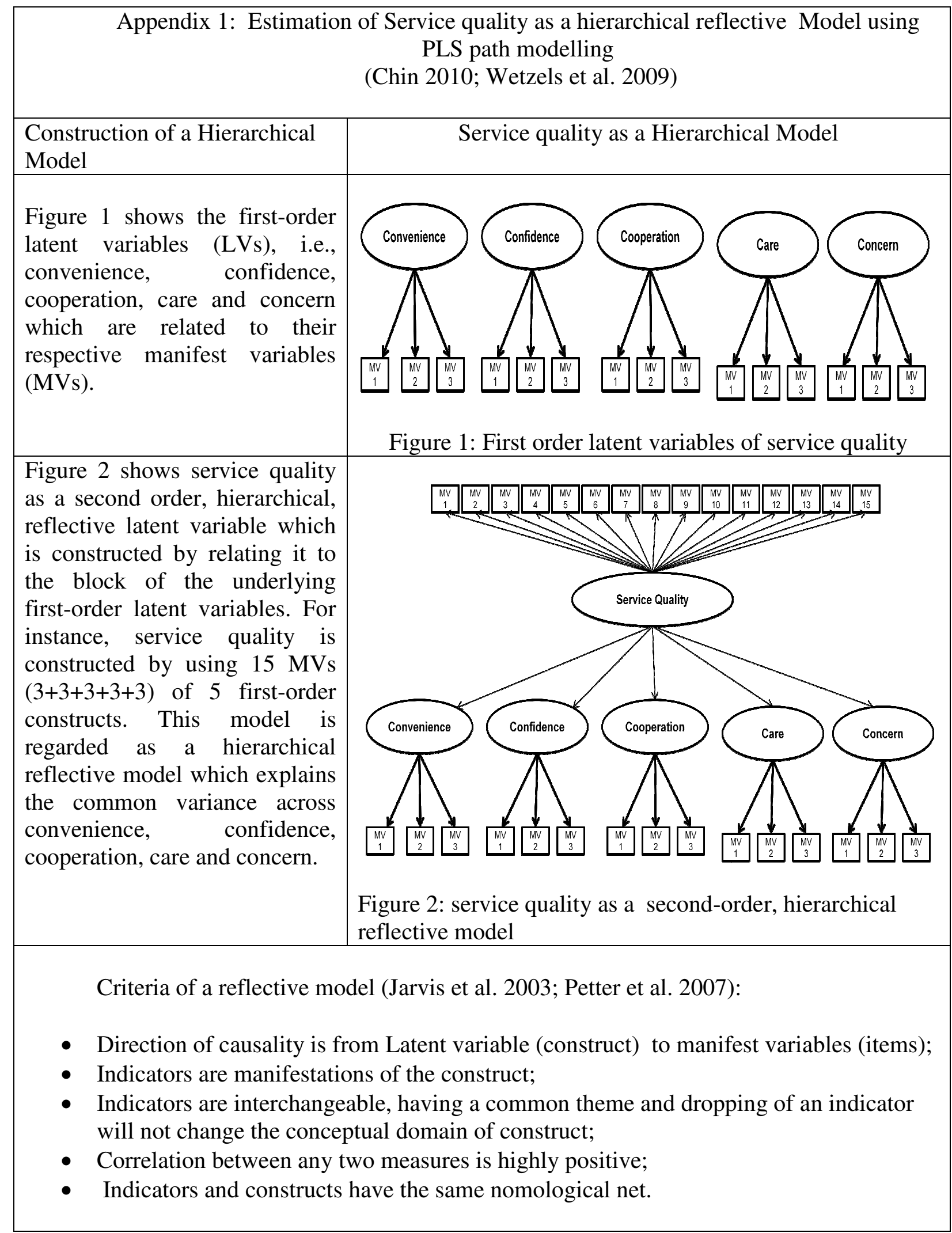




\section{References}

Ajzen, I., and Fishbein, M., 1980. Understanding attitudes and predicting social behavior. Englewood Cliffs, NJ: Prentice-Hall, 1980.

Akter, S. and Ray, P., 2010. mHealth-an ultimate platform to serve the unserved. IMIA Yearbook of Medical Informatics, Germany: Schattauer; 2010.

Akter, S., D'Ambra, J., and Ray, P., 2011. Trustworthiness in mHealth Information Services: An Assessment of a Hierarchical Model with Mediating and Moderating Effects using Partial Least Squares (PLS), Journal of American Society for Information Science and Technology, 62(1), 100-116.

Andaleeb, S. S., 2001. Service Quality Perceptions and Patient Satisfaction: A Study of Hospitals in a Developing Country, Social Science and Medicine, 52 (9), 13591370.

Anderson, E. W. and Sullivan M. W., 1993. The Antecedents and Consequences of Customer Satisfaction for Firms, Marketing Science 12 (2), 125-143 (Spring).

Athanassopoulos, A. D., 2000. Customer Satisfaction to Support Market Segmentation and Explain Switching Behaviour. Journal of Business Research, 47 (3), 191207.

Bagozzi, R. P., 2010. Structural equation models are modelling tools with many ambiguities: comments acknowledging the need for caution and humility in their use. Journal of Consumer Psychology, 20, 208-214.

Bansal, H. S., Taylor S. F and James Y. S., 2005. Migrating to New Service Providers: Toward a Unifying Framework of Consumers' Switching Behaviours. Journal of Academy of Marketing Science, 33(1), 96-115.

Baron, R. M. and Kenney D. A., 1986. The moderator-mediator variable distinction in social psychological research: Conceptual, strategic, and statistical considerations. Journal of Personality and Social Psychology, 51(6), 11731182.

Baroudi, J.J. and Orlikowski, W. J., 1988. A Short-Form Measure of User Information Satisfaction: A Psychometric Evaluation and Notes on Use, Journal of Management Information System, 4(4), 44-59.

Bernhardt, K. L. Donthu, N. and Kennett, P. A., 2000. A Longitudinal Analysis of Satisfaction and Profitability. Journal of Business Research, 47, 161-171.

Berry, L.L. and Bendapudi, N., 2008. Healthcare: a fertile filed for service research, Journal of Service Research, 10 (2), 111-122

Bernhardt, K. L. Donthu, N. and Kennett, P. A., 2000. A Longitudinal Analysis of Satisfaction and Profitability. Journal of Business Research, 47, 161-171. 
Bhattacherjee, A., 2001. Understanding information systems continuance. An expectation-confirmation model. MIS Quarterly, 25 (3), 351-370.

Bitner, M. J. and Brown, S.W., 2008. The Service Imperative Business Horizons, 51, 39-46 (January-February).

Boulding, W., Karla, A., Staelin R., Zeithaml V. A., 1993. A dynamic process model of service quality: from expectations to behavioural intentions. Journal of Marketing Research, 30:7- 27 (February).

Brady, M. K. and Cronin J.J., 2001. Some New Thoughts on Conceptualizing Perceived Service Quality: A Hierarchical Approach, Journal of Marketing, 65, 34-49 (July).

Brady, M.K., 2001. Robertson Christopher J. Searching for a Consensus on the Antecedent Role of Service Quality and Satisfaction: An Exploratory CrossNational Study, Journal of Business Research, 51 (1), 53-60.

Caruana, A., Ewing M. T. and Ramaseshan R. B., 2000. Assessment of the ThreeColumn Format SERVQUAL: An Experimental Approach, Journal of Business Research, 49 (I): 57-65.

Chatterjee S., Chakraborty S., Sarker S., Sarker S., Lau F. Y., 2009. Examining the success factors for mobile work in healthcare: a deductive study, Decision Support Systems, 46, 620-633.

Chin, W. W. (2001). PLS - Graph User's Guide Version 3.0., Houston, TX: Soft Modeling Inc.

Chin, W.W., Marcolin B. L, Newsted P. R., 2003. A partial least squares latent variable modelling approach for measuring interaction effects: Results from a Monte Carlo simulation study and an electronic-mail emotion/adoption study. Information System Research, 14(2), 189-217.

Chin, W. W., 2010. How to write up and report PLS analyses. In Esposito V, Chin WW, Henseler J, Wang H. (Eds.), Handbook of partial least squares: Concepts, methods and application, 645-689, Germany: Springer.

Chiou, J., Droge, C., \& Hanvanich, S., 2006. Does customer knowledge affect how loyalty is formed? Journal of Service Research, 5 (2), 113-124.

Choi, K.S., Cho W.H., Lee S., Lee H. K and Kim C., 2004. The relationships among quality, value, satisfaction and behavioural intention in health care provider choice: a South Korean study. Journal of Business Research, 57(8), 913-21

Choi, H., Lee M., Lm K.S. and Kim J., 2007. Contribution to quality of life: a new outcome variable for mobile data service, Journal of Association of Information System, 8(12), 598-618. 
Cohen, J., 1988. Statistical power analysis for the behavioural sciences (2nd ed.). Hillsdale: L. Erlbaum Associates.

Cohen J. and Cohen P., 1983. Applied multiple regression/correlation analysis for the behavioural sciences (2nd edition). Hillsdale, NJ: Erlbaum.

Cronin J. J and Taylor S.A., 1992. Measuring service quality: a re-examination and extension. Journal of Marketing, 56 , 55 - 68 (July).

Dagger T. S., Sweeney J.C. and Johnson L.W., 2007. A hierarchical model of health service quality: scale development and investigation of an integrated model. Journal of Service Research, 10 (2), 123-142.

Dabholkar P.A., Thrope D.I., Rentz J.O., 1996. A measure of service quality for retail stores: scale development and validation. Journal of Academy Marketing Science, 24(1), $3-16$.

Dabholkar P. A., Shepherd D.C., Thorpe D.I ., 2001. A Comprehensive Framework for Service Quality: An Investigation of Critical Conceptual and Measurement Issues through a Longitudinal Study, Journal of Retailing, 72 (2), 139-173.

Dagger T.S. and Sweeney J. C., 2006. The effect of service evaluations on behavioural intentions and quality of life. Journal of Service Research , 9(1), 3-18.

Donabedian, A., 1992. Quality Assurance in Health Care: Consumers' Role, Quality of Health Care, 1, 247-251.

Efron B. and Tibshirani R. J., 1993. An Introduction to the Bootstrap, New York: Chapman and Hall.

Eskildsen J, Kristensen K., 2003. The predictive power of intangibles. Measuring Business Excellence 7(2): 46-54.

Ferrans C.E., Powers M.J., 1992. Psychometric Assessment of the Quality of Life Index, Res Nurs Health, 15, 29-38.

Fornell, C. A., 1992. National Customer Satisfaction Barometer: The Swedish Experience, Journal of Marketing, 56, 6-21(January).

Fornell C. and Larcker D. F., 1981. Evaluating Structural Equation Models with Unobservable Variables and Measurement Error, Journal of Marketing Research, 18(1), 39-50.

Jarvis C. B., MacKenzie S. B. and Podsakoff P. M., 2003. A Critical review of construct indicators and measurement model misspecification in marketing and consumer research. Journal of Consumer Research, 30, 199-218.

Geisser, S. and Eddy, W., 1979. A predictive approach to model selection. Journal of American Statistical Association, 74, 153-160 
Giesh, J. L. and Cote J.A., 2000. Defining consumer satisfaction, Academy of Marketing Science Review (1).

Gronroos, C., 1984. A Service Quality Model and Its Marketing Implications, European Journal of Marketing, 18 (4), 36-44.

Hair, J., Ringle, C.M., \& Sarstedt, M. (2011). PLS-SEM: indeed a silver bullet. Journal of Marketing Theory and Practice, 19 (2), 139-151.

Heisel, M. J. and Flett, G. L., 2004. Purpose in Life, Satisfaction with Life, and Suicide Ideation in a Clinical Sample, Journal of Psychotherapy and Behaviour Assessment , (26) 2, pp. 127-135.

Homburg C. and Giering, A., 2001. Personal characteristics as moderators of the relationship between customer satisfaction and loyalty - an empirical analysis, Psychology and Marketing 2001, 18 (1), 43-66.

Howard, J.A. and Sheth J.N., 1969. The theory of buyer behaviour , Newyork: John Wiley and Sons.

Hulland, J. Ryan, M.J., \& Rayner, R. K. (2010). Modeling customer satisfaction: a comparative performance evaluation of covariance structure analysis versus partial least squares, in Handbook of Partial Least Squares: Concepts, Methods and Application. Esposito Vinzi, V.; Chin, W.W.; Henseler, J.; Wang, H. (Eds.), Springer, Germany, 307-325.

Iacobucci, D., 2008.Mediation analysis. Thousand Oaks, CA: Sage.

Ivatury G., Moore J., Bloch A., 2009. A doctor in your pocket: health hotlines in developing countries. Innovations: Technology, Governance, Globalization, 4(1), 119-153.

Jia, R., Reich, B. H., \& Pearson J.M., 2008. IT service climate: an extension to IT service quality research, Journal of AIS, 9 (5), 294-320.

Jun M., Peterson R. T, Zsidisin G. A.,1998. The Identification and Measurement of Quality Dimensions in Health Care: Focus Group Interview Results, Health Care Management Review, 23 (4), 81-96.

Kahn, J.G., Yang, J., and Kahn, J.S., 2010.The potential roles of mHealth in developing economies: can they be realized? Health Affairs, 2, 254-61.

Kaplan B., Litewka S., 2008. Ethical challenges of telemedicine and telehealth. Cambridge Quarterly Healthcare Ethics, 17, 401-416. 
Limayem M., Hirt, S. G., Cheung C. M.K., 2007. How habit limits the predictive power of intention: the case of information systems continuance. MIS Quarterly ,31(4):705-737.

Ma, Q., Pearson, M., and Tadisina, S. 2005. An exploratory study into factors of service quality for application service providers. Information \& Management, 42(8), 1067-1080.

Mechael, P., 2009. The case for mHealth in developing countries. Innovations: Technology, Governance, Globalization, 4(1), 103- 118.

Montoya, M.M, Massey A.P., Khatri, V. 2010. Connecting IT services operation to services marketing practices, Journal of Management Information System, 26 (4), 65-85.

O'Connor, S.J., Shewchuk, R.M., Carney, L.W., 1994. The Great Gap: Physicians' Perceptions of Patient Service Quality Expectations Fall Short of Reality, Journal of Health Care Marketing, 14 (2), 32-39.

Oliver, R.L., 1980. A Cognitive Model for the Antecedents and Consequences of Satisfaction, Journal of Marketing Research, 17, 460-469

Oliver, R.L., 1993. A conceptual model of service quality and service satisfaction. In: Swartz TA, Bowen DE, Brown SW, editors. Advances in services marketing and management. Research and practice ; 2: 65- 80, Greenwich, CT: JAI Press.

Oliver, R.L., 1997. Satisfaction: a behavioural perspective on the consumer. Boston, MA: Irwin-McGraw-Hill.

Ostrom, A.L., Bitner, M.J., Brown, S. W., Burkhard, K.A., Goul, M., Daniels, V. S., Demirkan, H., and Rabinovich, E., Moving forward and making a difference: Research priorities for the science of service," Journal of Service Research, 2010; 13 (1): 4-36.

Parasuraman, A., Zeithaml, V. A., Berry, L. L. (1985). A conceptual model of service quality and its implications for future research, Journal of Marketing, 49, 4150 .

Parasuraman, A., Zeithaml, V. A, Berry L. L., 1988. SERVQUAL: A Multiple- Item Scale for Measuring Consumer Perceptions of Service Quality. Journal of Retailing, 64 (1), 12-37.

Parasuraman, A., Zeithaml, V. A., \& Malhotra, A., 2005. E-S-QUAL: a multiple-item scale for assessing electronic service quality. Journal of Service Research, 7(3), 213-233.

Porter, M.E. and Teisberg E. O., 2006. Redefining health care: Creating value based competition on results, Boston: Harvard Business School Press. 
Reynolds, N., \& Smith, A. (2010). Assessing the impact of response styles on crosscultural service quality evaluation: a simplified approach to eliminating the problem. Journal of Service Research, 13(2), 230-243.

Rust, R. T. and Oliver, R.L. 1994. Service Quality: Insights and Managerial Implications from the Frontier, in Service Quality: New Directions in Theory and Practice, Roland T. Rust and Richard L. Oliver, eds. Thousand Oaks, CA: Sage, 1-19.

Saila, T., Mattila, E., Kaila, M., Aalto, P., Kaunonen, M., 2008. Measuring patient assessments of the quality of outpatient care: a systematic review. Journal of Evaluation and Clinical Practice, 14(1), 148-154.

Sirgy, J.M. 2001. Handbook of Quality of Life Research. Dordrecht, the Netherlands: Kluwer.

Sobel, M., Asymptotic confidence intervals for indirect effects on structural equation models. In S. Leinhardt (Ed.), Sociological Methodology 1982; 290-312, JossyBass.

Straub, D. and Watson, R.T., 2001. Research commentary: transformational issues in researching IS and net-enabled organizations. Inform System Research, 12(4), $337-345$.

Stone, M. Cross-validatory choice and assessment of statistical predictions (with discussion). J. R. Statist. Soc. B 1974; 36, 111-147.

Szymanski, D.M. and Henard, D.H., Customer satisfaction: a meta analysis of the empirical evidence. Journal of Academy of Marketing science. 2001; 29(1): 1635 .

Taylor S. A. and Baker T. L., 1994. An assessment of the relationship between service quality and customer satisfaction in the formation of consumers' purchase intentions. Journal of Retailing, 70 (2), $163-78$.

Tenenhaus, M., Vinzi, V. E., Chatelin, Y.M. and Lauro, C. 2005. PLS path modelling. Computer Statistics and Data Analysis, 48 (1), 159-205.

Varshney, U., 2005. Pervasive healthcare: applications, challenges and wireless solutions, Communication of Association of Information System, 16(3), 57-72.

Voss, C. A., Roth, A.V., Rosenzweig, E.D., Blackmon, K., Chase, R. B., 2004. A Tale of Two Countries' Conservatism, Service Quality, and Feedback on Customer Satisfaction, 6(3), 212-230.

Westbrook, R.A., Sources of Consumer Satisfaction with Retail Outlets. Journal of Retailing, 1981; 57, 68-85 (Fall).

Wetzels, M., Schroder GO, Oppen VC. 2009. Using PLS path modelling for assessing hierarchical construct models: guidelines and empirical illustration. MIS Quarterly, 33(1), 177-195. 
Wold, H., 1982. Soft Modelling: The Basic Design and SomemExtensions, in Systems Under Indirect Observation: Causality, Structure, Prediction (Volume 2), K. G. Jöreskog and H. Wold (eds.), Amsterdam: North Holland, pp.1-54.

World Helath Organization. 2008. The world health report. Primary healthcare- now more than ever. (Geneva: WHO).

World Health Organization. 2011. mHealth: New horizons for health through mobile technologies: second global survey on eHealth, (Geneva: WHO).

Woodside, A. G., Frey, L. L and Daly, R. T., 1989. Linking service quality, customer satisfaction, and behavioural intention. Journal of Health Care Marketing, $9(4), 5-17$.

Zeithaml, V.A, Berry L. L. And Parasuranam A., 1996. The behavioural consequences of service quality. Journal of Marketing, 60, 31 - 46 (April).

Zeithaml, V. A., 2000. Service quality, profitability, and the economic worth of customers: what we know and what we need to learn. Journal of Academy of Marketing Science, 28(1), $67-85$. 